\title{
perifèria
}

Número 3, Diciembre 2005

www. periferia. name

\section{Lo viejo y lo nuevo. Una aproximación antropológica a los cambios socioculturales en las personas transplantadas}

\begin{abstract}
Montserrat Venturas Nieto - Antropología social y cultural, UAB ${ }^{1}$
\section{Resumen}

El transplante de órganos y tejidos se realiza en nuestra sociedad, a través de la donación, el altruismo y la solidaridad de los donantes. El presente artículo, fruto de una investigación en curso, parte del análisis en profundidad de las entrevistas realizadas a personas en lista de espera para transplante de órganos y personas que ya han pasado por el transplante. El objetivo de este estudio son las personas y los cambios socioculturales que experimentan. Uno de ellos es el generalizado sentimiento de agradecimiento.
\end{abstract}

\section{Abstract}

The transplantation of organs and tissues is done in our society through donation, altruism and the donor's solidarity. This article, part of an ongoing research, is devoted to the analysis of in-depth interviews to people waiting for transplantation. The main goal of this research is the people and the sociocultural changes that they suffer. One of the most common is the feeling of gratitude.

\section{Agradecimiento ... ¿a quién?}

Una de las constantes que he observado a lo largo de mi trabajo de campo es el sentimiento de agradecimiento que experimentan los trasplantados de corazón. Explicar este hecho es uno de los objetivos de este artículo. Empezaremos con el testimonio de un multitrasplante de órganos de una persona fallecida:

¿Agradecimiento? Mucho.

¿Agradecimiento? Muchísimo, porque el día que él estaba dentro para ponerle el corazón, y vi las neveras que traían los órganos, pensé...para él puede haber vida, para el otro...vida desde luego que no la hay, ósea eso es para dar gracias a la persona que lo dona (Fidela, esposa).

\footnotetext{
${ }^{1}$ Enviar correspondencia a: Montserrat Venturas Nieto [dracky@wanadoo.es].
} 


\section{perifèria}

Número 3, Diciembre 2005

www. periferia. name

¡Y cinco hicieron! (Fidela (esposa) ${ }^{2}$.

¡El pulmón también!, imagínate si a todos les ha ido como a mí.

Al señor del hígado le ha ido fantástico, porque estuvimos con él durante, bueno, ya le dieron el alta antes que a nosotros (Fidela, esposa).

Igual esa persona no lo había dejado ni escrito, y esos familiares, ¡chapó por ellos!, en fin, ichapo!, porque hacen algo fabuloso. Porque yo mismo el corazón que yo llevo..., ese día transplantaron a dos de riñón, uno de hígado, las córneas..., esto que yo sepa, el pulmón...

Sí a él sí. Es otra anécdota más respecto a todo lo que me has preguntado, que su mujer le decía a mi mujer, -nosotros ahora somos algo de familia. ${ }^{3}$

Este informante fue transplantado el pasado año de corazón y explica en la entrevista realizada, cómo a través de un único donante cinco personas fueron transplantadas esa noche y tuvieron la oportunidad de vivir. Él fue uno de ellos. Fidela, su esposa, explica en la entrevista sus sentimientos y sensaciones la noche en que transplantaban a su marido, una de las palabras que más se utilizan en su testimonio y en el de su marido es "vida" y la otra, "agradecimiento".

Agradecimiento es la palabra recurrente en todas las entrevistas realizadas, agradecimiento al donante. Sin donante, no hay transplante, sin donante no se puede reiniciar la vida; agradecimiento a la familia del donante que en un momento crítico ha donado los órganos de su ser querido; agradecimiento a la sociedad en la que viven, que hace posible poder realizar un transplante de órganos y que existan unas instituciones sanitarias con una tecnología suficiente para realizarlos; agradecimiento a las personas que lo realizan, al personal sanitario que está pendiente de ellos; agradecimiento al espacio hospitalario, donde se sienten protegidos, cuidados, "en buenas manos", en una palabra, agradecimiento a poder "seguir viviendo".

\footnotetext{
2 Entrevista 2003-15; 20

${ }^{3}$ Entrevista 2003-15;21
} 


\section{perifèria}

Número 3, Diciembre 2005

www.periferia. name

Es de gran importancia remarcar el papel que ejerce en todas las fases, tanto la previa al transplante como los posteriores controles, el "espacio hospitalario". Este espacio hospitalario, es un reducto donde incluso las emociones son biomedicalizadas. Muchas de las personas ante el grave "riesgo" en el que se encuentran, ponen su "cuerpo", sus emociones, en manos de ese "espacio" y del personal que en él se halla, sobre todo a la profesión médica que de alguna manera "ha de decidir por ellos /as".

Otro informante en lista de espera para transplante de corazón me cuenta sus sensaciones en esta espera, y cuáles son sus creencias:

Mira yo tengo fe en todos vosotros, médicos, enfermeras, en el hospital, y se que se hará todo lo posible para que vaya bien, si no va..., no es culpa de nadie, y también tengo fe en la persona y su familia que me han donado el corazón y hacen posible que siga viviendo. Éstas son mis creencias y estaré eternamente agradecido a esa familia e intentaré no defraudar a ese corazón que me han donado ${ }^{4}$.

En muchos casos, al recibir ese órgano donado, ese "regalo", algunas de las personas que lo reciben, lo viven como una deuda que contraen, con el /la donante, con la sociedad, etc. Después de unos tres meses de realizar esta entrevista, E.S.B fue transplantado de corazón, tuvo un postoperatorio muy complicado, estuvo unos cuatro meses ingresado en el hospital, pero ahora se está recuperando. Para él lo importante es que está vivo, ha tenido una oportunidad de "vivir" más, ese día recibió "vida".

Las personas que han pasado por un transplante de órganos, han recibido de la sociedad un "don". Este "don" es un "regalo" que han recibido o esperan recibir, lo viven realmente como "un regalo" que da vida, aunque en algunos de ellos y ellas, en su interior existe un sentimiento contradictorio, ya que para existir el "regalo", una persona ha tenido que morir:

\footnotetext{
4 Entrevista a E.S.B; 5.
} 


\title{
perifèria
}

Número 3, Diciembre 2005

www. periferia. name

\begin{abstract}
Yo tengo una imagen hecha de él, y esta dentro de mí, entonces... le hablo de nuestro corazón, porque pienso que no es mió, me lo han dado, me han dado una oportunidad de vivir más, pero claro me duele mucho que haya tenido que faltar una persona tan joven, por eso te digo que nunca he sido capaz de pedir que me llegara un corazón, mi corazón no me lo permitía, porque sabía lo que significaba para otra persona, entonces...pienso en los padres, y lo que habrán pasado, y ... estoy muy agradecida, porque me han dado la vida, pero a la vez es...es un sentimiento de contraste, porque ha tenido que faltar él ${ }^{5}$.
\end{abstract}

En muchas de las entrevistas realizadas, siempre está latente el sentimiento de culpabilidad, de poder seguir viviendo, pero a través de una muerte.

Lo que nunca he sido capaz es de pedir un corazón para mí. A mí me decían, pídelo, porque si lo pides viene antes y tal, pero he sido incapaz. Que tenga que morir una persona es algo que cala mucho, que yo francamente nunca he tenido el valor de pedir, yo dije ¡Dios mío, cuando quieras!, nunca he tenido el valor de pedirlo, porque si lo hubiera pedido y hubiera llegado rápido, puede pasar ¿no?, me hubiera sentido culpable. ${ }^{6}$

Bueno, esto es una cosa que en cierta medida no quiero ni pensarlo, no me sentiré culpable, porque no ha sido culpa mía, pero vaya mala pata que para salvarse otro, haya tenido que morir alguien, pero de momento no hay otra forma. El sistema no lo he inventado yo, ni es cosa mía, es ley de vida. Si que es una cosa un poco morbosa, estas esperando que muera alguien, pero vaya yo no estoy esperando que se mate alguien, no lo deseo, si pasa y por suerte este corazón me sirve, mira...es la parte positiva. Has de pensar en positivo, no en negativo. ${ }^{7}$

\footnotetext{
${ }^{5}$ Entrevista 2004-11; 13

${ }^{6}$ Entrevista 2004-11;8

${ }^{7}$ Entrevista J.G.A;9
} 


\section{perifèria}

Número 3, Diciembre 2005

www. periferia. name

\section{El marco institucional de la donación de órganos}

El sistema español, está inspirado en los valores de voluntariedad, altruismo, gratuidad y ausencia de lucro en la donación. En la parte logística esta apoyado por la descentralización, esto hace que cada centro autorizado como transplantador se tenga su propia infraestructura y se quede con los órganos que se obtengan dentro de él, siempre que no exista una urgencia "0". Esta autonomía supone un incentivo para cada equipo. En todo este sistema de donación y transplante existe otra figura no tan popular como el cirujano, que es la encargada de la captación de los órganos y la organización de todo el proceso del transplante, el/la coordinador. Se trata de profesionales que están encargados de captar al posible donante, hablar con los familiares para que acepten la donación y solicitar los órganos. Todo esto esta basado en la ley $27 / 1979$.

El parlamento español aprobó el 27 Octubre de 1979, la ley sobre extracción y transplante de órganos. Cuyos puntos principales son:

- Indica quién es donante de órganos.

- Prohíbe cualquier intercambio económico con la donación o recepción de órganos para el transplante. Señala la gratuidad de la asistencia para el donante si es vivo y evitar cargas suplementarias a los familiares en caso de donantes fallecidos.

- Indica que la donación y los transplantes se realizan en centros autorizados.

- Indica los criterios a cumplir para el diagnóstico de muerte cerebral y los médicos que deben hacerlo.

- Los criterios que deben cumplir los centros extractores y transplantadotes.

- Los requisitos que se deben cumplir para averiguar y garantizar la voluntad del donante.

- La información que debe darse al receptor.

A partir de esta Ley 27/1979, se dictó el Real Decreto 411/1996 de 1 de Marzo que se regulan las actividades relativas a la utilización de tejidos humanos y el 30 de Diciembre de 1999 se dictó el Real Decreto 2070/1999, por el cual se regulan las 


\section{perifèria}

Número 3, Diciembre 2005

www. periferia. name

actividades de obtención y utilización clínica de órganos humanos y la coordinación territorial en materia de donación y transplante de órganos y tejidos. Estos Reales Decretos respetan la Ley de 1979 y definen de forma clara:

- La finalidad terapéutica en la extracción de órganos.

- Confidencialidad del donante y receptor del órgano.

- Gratuidad.

- Educación y formación.

- Promoción, publicidad, carácter voluntario, altruista y desinteresado.

La donación de órganos es un acto altruista por el cual una persona manifiesta la voluntad de que a partir del momento de su muerte, cualquier parte de su cuerpo que sea apta para el transplante puede ser utilizada para ayudar a otras personas que lo necesiten. Durante mi trabajo de campo, estoy realizando un cuestionario ${ }^{8}$ en la Coordinación de Transplantes del Hospital Clínic, donde se recogen los datos sociodemográficos, culturales, religiosos de las personas que acuden a dicho centro con la voluntad de ser donantes de órganos y realizarse el carné de donante. Así como sus motivaciones para hacerlo. La finalidad del cuestionario es hacer un análisis descriptivo de las personas que acuden a dicho centro para hacerse donante de órganos.

Si una persona se plantea ser donante, lo más importante es que comunique la decisión a sus allegados, ya que a ellos será a quién se les consulte la posibilidad de la donación después de su muerte, también es importante rellenar el carné de donante y llevarlo siempre junto con la documentación personal. Éstas son preguntas que consulto en mi cuestionario.

Cualquier persona puede ser donante potencial, siempre que en vida no haya manifestado su voluntad en contra de la donación de órganos. Las condiciones

\footnotetext{
${ }^{8}$ Cuestionario Donante de órganos. Realización propia.
} 


\section{perifèria}

Número 3, Diciembre 2005

www.periferia. name

clínicas en las que se encuentren en el momento de su muerte, son las que determinan los órganos y tejidos válidos para los transplantes.

Además de la donación de cadáver, se puede realizar también la donación en vida, siempre que esta no ponga en peligro la vida del donante. Se puede obtener un órgano entero (un riñón, por ejemplo), o la parte de un órgano (de un hígado, por ejemplo), también se pueden obtener tipos de tejido, como la membrana amniótica, la sangre de cordón umbilical, la médula ósea. La donación en vida, de acuerdo con la normativa vigente que regula estas posibilidades, se limitará a situaciones en las que se puedan esperar grandes éxitos con el transplante. En principio puede ser donante vivo cualquier persona adulta y sana, pero esta opción también comporta grandes riesgos, pues se trata de una intervención quirúrgica.

En caso de menores de edad y discapacitados, se ha de respetar la voluntad de las personas que tengan la patria potestad (Ley 30/1979).

Para poder ser donante de órganos y tejidos, la muerte se ha de producir en un hospital, con la finalidad de que el cuerpo se pueda mantener artificialmente hasta el momento de la extracción de los órganos.

Los motivos que regulan la donación de órganos y tejidos, son personales o bien familiares, ligados evidentemente a las experiencias personales y a las creencias de los individuos. Desde un punto de vista institucional existe una red una ordenación de la repartición de órganos en función de unas listas de espera.

La retórica en nuestra sociedad conceptualiza el "don" como gratuito y voluntario y los familiares que ceden los órganos lo viven como una "donación", es decir, una forma a través de la cual esa persona querida que ha fallecido siga haciendo el "bien", ayudando a vivir a otras personas, viviendo, pero en otro cuerpo. Este tipo de "don" moderno, no existía en la época que Marcel Mauss escribió su libro Essai sur le Don (1922). Veamos brevemente la historia de los trasplantes para entender la especificad de este "don". 


\section{perifèria}

Número 3, Diciembre 2005

www.periferia.name

\section{Historia de los transplantes}

Llamamos transplante al procedimiento por el cual se implanta un órgano o tejido procedente de un donante a un receptor. Existen dos tipos de transplantes.

- De órganos (riñón, hígado, corazón, pulmón, cornea, etc.)

- De tejidos (médula ósea, células endocrinas, etc,.)

Si nos centramos en los alotransplantes (órgano que procede de un individuo de la misma especie), el ejemplo típico e histórico es la transfusión sanguínea, que se realizó con éxito en 1901 cuando Lausteiner descubrió el sistema A.B.O. y gracias a ello se pudo visualizar el fenómeno del rechazo.

En 1954 se realizó con éxito el primer transplante renal en gemelos y se comenzaron a probar diversas drogas immunosupresoras, y a partir de aquí se realizaron una serie de transplantes. En 1963 Hardy realiza el primer transplante de riñón, al cual le siguió Starzl con el primero de hígado.

El 3 de Diciembre de 1967, en Ciudad del Cabo, Cristian Barnard, cardiólogo y cirujano sudafricano, realiza el primer transplante cardíaco, logrando así algo sólo probado en la teoría, logró transplantar con éxito, un corazón en medio de un gran debate científico y social, ya que el corazón era considerado un símbolo de afectividad.

Louis Washkansky de 55 años con un problema incurable en su órgano vital, se pudo transplantar, gracias al corazón de una joven, Denise Darwall, víctima de un accidente de tráfico. El padre de la joven accedió a la donación de los órganos de su hija. Washkansky sobrevivió 18 días.

En 1978 aparece la Ciclosporina A, posibilitando un control aceptable del rechazo.

Durante el corto tiempo que constituye la historia de los transplantes de órganos, se fueron sucediendo diferentes etapas, y diferentes problemas éticos que se pueden agrupar en tres fases: 


\section{perifèria}

Número 3, Diciembre 2005

www. periferia. name

- Fase experimental: desde 1950 - 1975. Se plantean todos los problemas éticos de la experimentación con seres humanos.

- Fase de consolidación: desde 1975 - 1983. Se legisla acerca de la muerte cerebral y sobre los requisitos que debe cumplir el proceso de donación y transplante.

- Fase terapéutica: esta etapa se inicia con la aparición de la Ciclosporina A y con ella una efectiva inmunosupresión, el transplante comienza a ser realmente útil. Esta fase tiene que ver con la escasez de recursos y órganos, así como con la justa elección de receptores.

El concepto de muerte ha ido variando a lo largo de la historia, la muerte natural tradicionalmente ha sido la muerte cardiopulmonar. A mediados del siglo XX, surge el concepto de muerte cerebral. Este concepto surgió en la XXII Reunión Medica Mundial celebrada en Sydney a partir de la cuestión ¿qué dota de naturaleza humana a un ser vivo?

La muerte cerebral se define, según la Presiden'ts Comission's

Un individuo está muerto cuando le ha sobrevenido o bien el cese de las funciones respiratorias y circulatorias, o bien el cese irreversible de todas las funciones cerebrales, incluyendo el tronco cerebral. La determinación de muerte cerebral debe realizarse de acuerdo a los estándares médicos aceptados.

Con esta definición se perfila así, una definición no estática sino permisiva con los cambios científicos y culturales.

Actualmente en Cataluña, la donación de órganos y tejidos va en aumento. La población catalana está entre la más solidaria del mundo en cuanto a la donación de órganos y tejidos. Sólo el $20 \%$ de los ciudadanos se negaron a la donación en el 2005, pero esta negación fue un poco más alta que en el 2004 , que fue del 18,4\%, esto también puede verse influenciado por el recelo de la población inmigrante en cuanto a la donación de los órganos de un ser querido, ya que en sus países de origen no es una práctica habitual. 


\section{perifèria}

Número 3, Diciembre 2005

www.periferia. name

\section{La donación de órganos y la teoría antropológica}

Pienso que las personas que no lo tienen pensado, en ese momento tener que dar los órganos de tu ser querido...no se si me explico. Hay veces que ya lo tienes pensado, tienes más claro lo que hacer. En caso de que pase lo das, porque a ti te lo han dado. Pero si no te ha pasado nada, no tienes ninguna experiencia y pensar que esa persona se ha de decidir en ese momento. Yo no quiero dar sólo mis órganos, yo quiero que mi cuerpo, lo doy a la ciencia y que hagan lo que puedan, a mi no me va a servir para nada. ${ }^{9}$

"En caso de pase lo das porque a ti te han dado" Con esta frase, mi informante mi remite al fenómeno del "don". Marcel Mauss nos mostró que "donar", encadena tres obligaciones "donar", “ recibir “, "devolver". Estas conclusiones sobre el fenómeno del "don" fueron extraídas a través del análisis de dos sociedades de las llamadas primitivas; el estudio realizado por Malinowski en las islas Tobriand, en el Pacífico occidental, y el realizado por Boas en los grupos kwakiult del noroeste americano. El kula es un gran sistema de intercambio intertribal que se extiende en sobre todas las islas Tobriand de la Polinesia, por el medio del cual se hacen circular tanto objetos preciosos de uso cotidiano, como alimentos, fiestas, servicios rituales y sexuales, hombres y mujeres. Los intercambios se realizan según la descripción de Malinowski, de acuerdo con un movimiento circular.

El otro tipo de estudio, el potlatch, fenómeno de intercambio en el oeste norteamericano, adopta distintas formas, alguna de ellas relacionada con la destrucción, por ejemplo se sacrifican esclavos, se queman aceites preciosos, se tiran al mar objetos de cobre, se queman mansiones, y todo ello no sólo para demostrar potencia o riqueza, sino también para sacrificar a los espíritus y a los dioses.

\footnotetext{
${ }^{9}$ Entrevista 2003-15;15-16
} 


\section{perifèria}

Número 3, Diciembre 2005

www. periferia. name

Ambos fenómenos, el kula y el potlatch, consisten en esencia dos acciones, para unos es "dar", para los otros es "recibir", los que en un momento don donadores, en otro son donatarios. Las obligaciones son tres: "dar", "recibir", "devolver".

A partir de Marcel Mauss, otros autores han estudiado el fenómeno del "don", entre ellos Maurice Godelier, este nos explica en su libro "El enigma del Don";

Un don es pues un acto voluntario, individual o colectivo, que pueden o no haber solicitado aquel, aquellas o aquellos que lo reciben ${ }^{10}$.

Evidentemente las personas que deben pasar por un transplante de órganos, no solicitan directamente el órgano necesario, al menos en nuestra sociedad, pero sí que lo necesitan para poder seguir viviendo. En este sentido son otras personas las encargadas de solicitar esos órganos, unos/as intermediarios que están entre el donante y el receptor. La persona que recibe el órgano, no establece una relación directa con el receptor, pero sí se siente deudor, pero mi pregunta es ¿con quién? ¿Y a quién o quienes retornarán ese "don", ese "regalo" que reciben del donante, pero a través de la sociedad, de las instituciones?

Mauss a través de sus tres condiciones del "don", "dar", "recibir" y "devolver", intentaba explicar por qué se dona, pero falta saber por qué se devuelve. Mauss aducía la versión emic según la cual

(...) que las cosas donadas tienen un espíritu que las obliga a retornar a la persona que en principio las ha poseído y donado.

\section{Como Godelier nos explica}

El enigma se resuelve por el hecho de que en las cosas donadas hay una fuerza que las obliga a circular y a volver junto a su propietario. La solución se encuentra pues del lado de los mecanismos espirituales, de las razones

\footnotetext{
${ }^{10}$ Godelier, M. (1998). El enigma del Don. pp. 25.
} 


\section{perifèria}

Número 3, Diciembre 2005

www. periferia. name

morales y religiosas, de las creencias que prestan un alma, un espíritu, a las cosas, un espíritu que las obliga a retornar ${ }^{11}$.

Mauss analizó los conceptos polinesios de hau y mana. Pero en nuestro estudio es interesante saber, por qué las personas donan o no los órganos de un ser querido fallecido, o por qué voluntariamente se hace una persona donante de órganos. También es de gran interés saber cómo viven y sienten las personas transplantadas el hecho de llevar un órgano de otra persona, qué les trasmite, qué sensaciones tienen 0 , por el contrario, si es tan formidable el poder de la biomedicina y la técnica, que se biomedicalizan las emociones, las creencias y no se deja "espacio" libre para pensar de forma autónoma.

Mary Douglas (1996), sigue la idea de Marcel Mauss de que no existen donaciones libres. En mi trabajo de investigación esto puede ir ligado con la sensación de tranquilidad con la que se quedan algunos de mis informantes ya transplantados, al pensar y saber que ellos también han sido donantes, donando la parte de su corazón extraído que se podía utilizar. Ellos/as han recibido un "don", una donación altruista, voluntaria y desinteresada, pero al mismo tiempo saben que han dado un "contradon", con las partes de su corazón que se podían utilizar. En muchas ocasiones, se da, pero se guarda un "algo", aunque este "algo", sea totalmente invisible, sea sólo la sensación interna de que se ha "dado".

No he preguntado nunca de quién era, si, si, estoy muy agradecido a esa familia que dieran ese órgano y punto. Y yo también, de lo que del corazón me sacaron, bueno aprovecharon alguna válvula, y no se que más. Me hicieron firmar para ver si lo quería dar y obviamente, claro que lo di, y no me ha pasado nunca por la cabeza donde ha ido a parar, no, eso es una cosa que toca a quién toca y punto ${ }^{12}$.

Es interesante, en este punto, analizar el "Concepto de Riesgo" que estudia Mary Douglas, ligado evidentemente a la sociedad en la cual se vive. Como la autora nos

\footnotetext{
${ }^{11}$ Godelier, op. cit. pp30.

12 Entrevista 2003-11;8
} 


\section{perifèria}

Número 3, Diciembre 2005

www.periferia.name

explica, las nociones de riesgo son construidas culturalmente, y enfatizan unos aspectos del peligro, pero al mismo tiempo ignoran otros. Con esto podemos ver que la noción de "riesgo", esta construida según la sociedad en la que se vive y que esta cultura de "riesgo", es cambiante según la clase social a la que se pertenece. En el tema del transplante de órganos, sabemos que en muchas sociedades, las personas afectadas no pasan de la fase de "riesgo peligro", ya que no hay alternativas, ni posibilidades de pasar a la fase de "riesgo aventura", ya que en su sociedad y por la clase social a la que pertenecen, no tienen acceso a un transplante de órganos.

Siguiendo a Mary Douglas con el análisis del riesgo, es un análisis de la cultura de la sociedad estudiada, esta cultura esta impregnada y forma parte de la percepción de las personas. El lenguaje del "riesgo" en la medicina, es un lenguaje probabilístico. Cuando se les explica a mis informantes, previo al transplante, los resultados de los transplantes de determinado órgano y ellos/as han de entrar a asumir ese "riesgo", se les explica en números probabilísticas, en tantos por cien, centrados en los resultados de determinado hospital transplantador. Las personas asumen o no entrar a formar parte de ese "riesgo", lo asumen para someterse a un transplante. Ese "riesgo", evidentemente tiene un fuerte arraigo cultural en cada sociedad. Esta aceptación de riesgos, tiene más connotación social y cultural, de creencias, que de aceptación de probabilidades y números. Nuestra cultura occidental tiene un gran sesgo cultural donde asumimos y aceptamos determinados "riesgos". También ello forma parte de un determinado "orden social".

Mary Douglas, trata el "riesgo" como "categoría social", entiende que las personas aceptan los riesgos a parte de la adhesión a una determinada forma de sociedad. Evidentemente estamos en una sociedad que promociona los transplantes, los avances tecnológicos en la medicina.

La cuestión de los niveles aceptables de riesgo forma parte de la cuestión de los niveles aceptables de vida y de los niveles aceptables de moralidad y decencia; y no se puede hablar con seriedad del aspecto del riesgo, mientras 


\section{perifèria}

Número 3, Diciembre 2005

www. periferia. name

se evita la tarea de analizar el sistema cultural en el que se han formado los otros niveles ${ }^{13}$.

Las características de la modernidad, han cambiado los parámetros de "riesgo" y de "peligro", al mismo tiempo ofrecen otras posibilidades de "vivir", a través de otros cuerpos que han dejado ya de "vivir". Por ello, a través de la muerte de una persona, se ha podido donar los órganos y seguir viviendo en otro cuerpo. Anteriormente nacer y morir eran dos etapas que marcaban la vida de las personas. El transplante de órganos y tejidos era algo impensable sólo pensable en la ciencia ficción, en la literatura. La definición del principio y del fin del cuerpo humano, estaba marcado por las leyes biológicas. A través de los nuevos avances se crea la necesidad de definir y pensar en la relación existente entre el cuerpo humano y la identidad individual.

En las entrevistas realizadas en mi trabajo de campo he podido escuchar todo tipo de razonamientos, desde los más pragmáticos a los más espirituales. Como me explicaba una informante sobre los sentimientos que tenía hacía el donante y a sus nuevos órganos:

Si, bueno, es que para mí es..."mi hermano corazón y mi hermano riñón", es que es del mismo, ósea es, me entiendes es del mismo donante, para mí, yo lo pregunté, se lo pregunté al cirujano, es de un chico, había sido un accidente de moto. En mis oraciones está, le hablo..., y me he hecho una imagen física de él, esta dentro de mí, entonces... entonces, le hablo de nuestro corazón, porque pienso que no es mío, me lo han dado, me han dado una oportunidad de vivir más ${ }^{14}$.

En las entrevistas realizadas a personas que han donado los órganos de su ser querido fallecido, se evidencia el sentimiento o la sensación que queda en ellos/as de que no todo de su ser querido ha muerto, si no que de alguna manera los órganos donados siguen viviendo en otras personas, sigue allí, aunque esté en otro cuerpo.

\footnotetext{
${ }^{13}$ Mary Douglas (1996). La aceptabilidad del Riesgo según las ciencias sociales. Pp: 127

${ }^{14}$ Entrevista 2004-11; 12-13
} 


\section{perifèria}

Número 3, Diciembre 2005

www. periferia. name

Este vivir en otro cuerpo, es el "don" que realizan a las personas que lo necesitan y revierte en el "agradecimiento" que sienten los receptores hacía el donante y la sociedad. En las entrevistas realizadas a los informantes transplantados de corazón, un tipo de devolución del "don" recibido está presente en el "agradecimiento" generalizado. Evidentemente no pueden demostrar este agradecimiento ni al donante, ni a su familia, ya que es totalmente anónimo, pero este agradecimiento, al no poder ser canalizado, revierte en la sociedad, en el centro hospitalario donde se ha realizado el transplante, en la institución y de alguna manera es un agradecimiento que llevan en su interior para siempre en la nueva "vida" que están viviendo.

Ingold $^{15}$ ilustra muy bien este tipo especial de relación social (Ilustración 1 ). En este gráfico de Ingold, el "don" se incluye dentro del cuerpo, y no queda fuera, por lo tanto la devolución del "don", está incluido dentro de una comunidad moral, la devolución es a la sociedad misma. Una forma de devolución de ese "don", es el “agradecimiento

\footnotetext{
${ }^{15}$ Ingold, Tim (1986). Evolution and Social Life. Cambridge University.Pp267
} 


\section{perifèria}

Número 3, Diciembre 2005

www.periferia. name

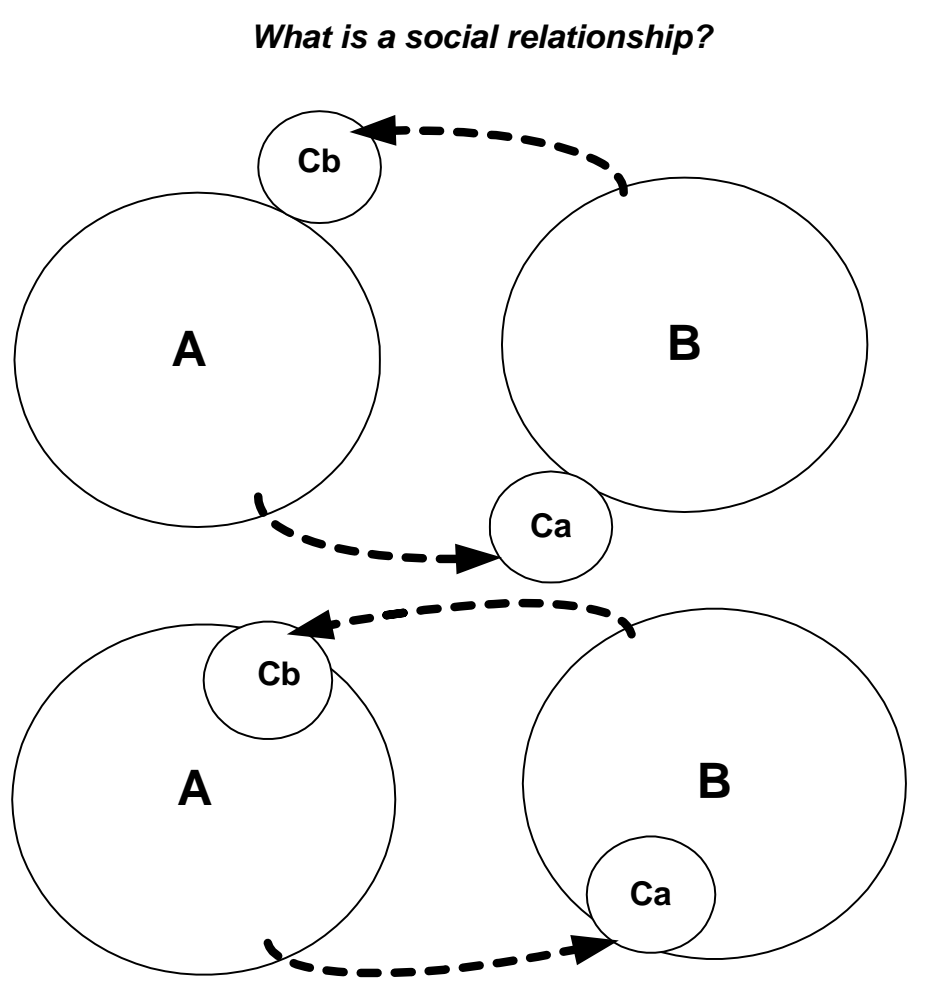

I lustración 1. ¿Qué es una relación social?

La forma en que mis informantes se expresan cuando hablan del "don", del "regalo" que han recibido es variable. Algunos/as quieren creer que el regalo les viene de una "mujer", quizás simbolizan lo bello del "regalo", lo bello de la "donación", con la imagen de una mujer "joven y guapa", con lo femenino. Esto me lo cuenta un informante ya transplantado de corazón el pasado año: 


\section{perifèria}

Número 3, Diciembre 2005

www. periferia. name

Yo desde el primer día lo he dicho, el corazón es de una chica joven y guapa. $\mathrm{Ha}$ de ser de una persona muy guapa para que haga esto, si, si, todo el mundo que estaba en ese corazón, debía ser muy "guapo", fue un entorno que se presto a hacerlo, eso $\mathrm{sí}^{16}$.

Mi informante (2003-07), enlaza el hecho de la "donación" con la belleza, la juventud, lo bonito, las fases bonitas de la vida.

Otros testimonios al hablar de la "donación", agradecen esa donación a la familia de la persona que ha sido donante:

La persona que hace esto, bueno...es para hacer un monumento a la familia, ya que la persona muerta, ya no se entera, pero es fabuloso, una persona que no tiene nada que hacer ya...y sabiendo que sus órganos van a salvar otras vidas.., eso es....17

En este caso el "donante", queda en un segundo plano, en una situación totalmente liminal y el agradecimiento revierte a sus familiares y a la institución-sociedad que hace posible ese transplante.

Es importante aquí remarcar el anonimato visible del donante en todo el periodo en el cual el órgano se separa del cuerpo. En este momento el órgano extraído entra en un periodo que denomino en mi trabajo de investigación, "fase liminal del órgano". En esta fase el órgano es preparado y conservado hasta su implantación en el cuerpo del receptor. Este órgano se extrae de un cuerpo que puede pertenecer a un hombre, a una mujer y posteriormente es implantado en un cuerpo receptor, que también puede pertenecer a uno u otro sexo. Durante esta fase, el órgano esta vacío de contenido y de todas las propiedades socioculturales que en su anterioridad le caracterizaban, esta desposeído de todo y su función es la espera a ser implantado en otro cuerpo. Esta es una fase totalmente asexuada, o también

\footnotetext{
${ }^{16}$ Entrevista 2003-07; 20
} 


\section{perifèria}

Número 3, Diciembre 2005

www. periferia. name

en un periodo de bisexualidad, un periodo de transición entre estados diferenciados.

Las propiedades socioculturales del "periodo liminal", fueron caracterizadas por Arnold van Gennep, con el nombre de "rites de passage". Victor Turner nos explica en su libro La Selva de los Símbolos, que "el propio van Gennep definió los “rites de passage", como ritos que acompañan a cualquier tipo de cambio de lugar, de posición social, de estado o de edad" (Turner , XXXX) ${ }^{18}$.

El término estado, puede también aplicarse a las condiciones ecológicas, o a la situación física, mental o emocional en que una persona o un determinado grupo puede encontrarse en un momento concreto. Una determinada persona puede, así, hallarse en estado de buena o mala salud ${ }^{19}$.

El órgano u órganos extraídos del cuerpo-donante, son guardados en recipientesneveras, conservados en soluciones que conservan el órgano y se trasladan hasta el hospital-transplantador donde se encuentre el receptor, para ser implantados en el cuerpo. Esto puede ser otra ciudad u otro país, según la conservación del órgano. Durante este proceso muchos profesionales gestionan y coordinan este trabajo.

Un informante ya transplantado me explica su percepción sobre lo que es un órgano, en su caso, lo que es él "corazón":

El corazón no hace referencia a que una persona sea buena o mala. Un buen corazón o un mal corazón no tiene nada que ver una cosa con otra. Es un simbolismo exagerado que se le ha dado, en cuanto a que, no porque la persona pobre que dejo de vivir, y me pasaron el corazón a mí, yo no seré ni mejor, ni peor por ese corazón. Yo seré mejor o peor por mi actitud frente a la vida, frente a la sociedad, frente a muchas circunstancias... ${ }^{20}$

En los comentarios y explicaciones de las personas transplantadas se evidencia la "bisexualidad" del órgano, característica del "periodo liminal":

\footnotetext{
${ }^{18}$ Turner,V. (1980). La Selva de los Símbolos. pp. 104.

19 Turner, op. cit. Pp. 103.

${ }^{20}$ Entrevista a informante 2003-07;2.
} 


\section{perifèria}

Número 3, Diciembre 2005

www. periferia. name

$\mathrm{Si}$, esto es una curiosidad que me lo pregunta casi todo el mundo, esto es una curiosidad general. Si, y que se siente, yo lo único que se, es que era de una persona más joven que yo, y no se nada más. Y se que por lo menos murió en el Clínic, porque el otro se que venía de...Tortosa, y la verdad, no se si es de un hombre o de una mujer, no lo sabemos..., de quién era, hombre o mujer, no lo hemos sabido nunca, y que sientes, como se vive, es una curiosidad que tiene todo el mundo. Yo les digo que igual, que no siento nada, es que la gente se piensa, no se, que se deben sentir cosas extrañas, les digo pues no siento nada ganas de vivir, más ganas de vivir que nunca, y más fuerza de la que he tenido en muchos años... ${ }^{21}$

Como decíamos al inicio de este trabajo, otra de las palabras recurrentes en todas las entrevistas realizadas es "vida". La palabra "vida", esta presente en todos los comentarios, sienten que ese "don", ese "regalo" que les han ofrecido les ha dado "vida", cuando su propia "vida" se apagaba, y choca con el sentimiento que tienen presente de que otra persona ha tenido que morir, para poder ellos / as "vivir".

La esposa de un informante me explica:

Porque el día que estaba él dentro para ponérselo, y vi las neveras que traían los órganos, pensé... para él puede haber vida, para el otro desde luego vida no la hay, ósea esto es para dar gracias a la persona que lo dona...22

"Agradecimiento", siempre agradecimiento, pero sí es cierto que las personas que han pasado por este proceso hablan con gran respeto y sienten un gran agradecimiento a todo ello, pero también se encuentra un cierto pragmatismo hacía la situación. La causa puede ser la espera del transplante, la enfermedad, el miedo a la muerte y también creo que es de gran incidencia la forma en las que en el mundo Occidental se trata a la enfermedad y al órgano, como partes y compuestos de una maquinaria que hace funcionar el cuerpo. Nuestra actual concepción del "cuerpo", está vinculada a la modernidad y al individualismo como elemento constituyente de la estructura social, con el pensamiento racional, positivo y laico

\footnotetext{
${ }^{21}$ Entrevista a informante 2003-15; 18-19.

22 Fidela, esposa informante, 2003-15.
} 


\section{perifèria}

Número 3, Diciembre 2005

www. periferia. name

sobre la naturaleza y con una gran incidencia de la historia de la medicina que da y proporciona un saber oficial sobre el "cuerpo", la "vida" y la "muerte". Sin embargo, los trasplantes hacen necesarias nuevas definiciones de identidad del cuerpo, de las partes del cuerpo, de la persona y de la muerte.

Perder mi corazón, pues como te lo diría...yo lo quise, y de hecho lo tengo en mente, a veces me gustaría escribir algo sobre todo esto. A veces es tan agobiante, los sentimientos se amontonan, entonces lo tengo en mente, a mi "viejo corazón", al viejo, y a mi "nuevo corazón", y tengo que escribir, porque lo necesito, los sentimientos se me amontonan, pero el pulso aún me tiembla ${ }^{23}$.

Mira normalmente se dice igracias a Díos!, yo digo, vale, gracias a Díos, pero...igracias al donante!, sin donante... no hay transplante ${ }^{24}$.

\section{I nvestigación en curso}

La investigación que estoy realizando se divide en dos ejes, por un lado "las personas que han pasado o deben pasar por un proceso de transplante de órganos" y por otro lado "la vida social del órgano", todo su circuito social.

En el primer eje de investigación, la unidad de análisis son las personas, el análisis de sus redes personales en la fase pretransplante y postransplante. El estudio de estos cambios nos puede ayudar a entender hasta qué punto se transforman las condiciones objetivas de su existencia cotidiana y cómo se relacionan esas condiciones con los discursos y las emociones. De esta forma hemos podido estudiar sus narrativas, ¿cómo han pasado por este proceso, qué sienten, qué emociones tienen, cómo han vivido la espera del órgano que necesitan, qué emociones tienen con ese órgano nuevo, cómo son y han sido sus vivencias con la familia, amigos, vida laboral, instituciones hospitalarias, asociaciones. Es decir, la vida cotidiana de estas personas.

\footnotetext{
${ }^{23}$ Entrevista 2004-11; 18.

${ }^{24}$ Entrevista 2004-10:6
} 


\section{perifèria}

Número 3, Diciembre 2005

www.periferia. name

El segundo eje de análisis en mi investigación ha sido "la vida social del órgano", todo el circuito por el cual ha tenido que pasar hasta llegar al receptor, la red institucional existente alrededor del "órgano", las regulaciones, los sistemas legislativos, políticos, la parte logística, las instituciones hospitalarias y los propios "donantes". En este punto he realizado entrevistas a personas que han sido "donantes vivos" a un familiar suyo y personas que han donado los órganos de un familiar fallecido. También hemos realizado un cuestionario de donantes de órganos, donde las personas que quieren ser donantes y hacerse el carné de donante, rellenan los datos de un cuestionario con la finalidad de conocer las variables sociodemográficas, el tipo de religión que profesan, los conocimientos y las motivaciones. Este cuestionario se administra en la unidad de Coordinación de Órganos del Hospital Clínic de Barcelona y es totalmente voluntario.

En este momento estoy estudiando las redes personales de las personas que han sido transplantadas y a las que en su momento ya entrevisté en su fase pretransplante, con la finalidad de conocer los cambios que se han producido en su vida cotidiana. Paralelamente hemos identificado un conjunto de organizaciones que dan soporte a las personas desplazadas de su lugar de origen para realizarse un transplante.

En conjunto esperamos poder estudiar tanto el ambiente social de las personas trasplantadas y sus cambios antes y después de la operación, como el ambiente institucional que rodea al órgano, a los donantes vivos, a los familiares, a los cuidadores y cuidadoras, la vida social del órgano. Esperamos poder entender la naturaleza de los cambios que se operan en este contexto y ayudar a las personas y sus familias a mejorar, aunque solamente sea en una pequeña parte, sus condiciones de vida. 


\section{perifèria}

Número 3, Diciembre 2005

www.periferia. name

\section{Bibliografía}

Douglas, M. (1996). La aceptabilidad del riesgo según las ciencias sociales. Paidos Studio. Barcelona.

Godelier, M. (1996, orig.1988) El enigma del Don. Paidos. Barcelona.

Ingold, T. (1986) Evolution and Social Life. Cambrigde University.

Turner. V. (1997, orig. 1980) La Selva de los Símbolos. Siglo XXI. Madrid.

\section{Entrevistas}

Entrevista 2003-15. Realizada el 18 de Mayo 2005.

Entrevista E.S.B. Realizada el 24 de Enero 2005.

Entrevista 2004-11. Realizada el 1 de Marzo 2005.

Entrevista 2003-11. Realizada el 20 Enero 2005.

Entrevista 2003-07. Realizada el 25 Febrero 2005.

Entrevista J.G.A. Realizada el 28 de Julio 2005.

Entrevista 2004-10. Realizada el 20 Enero 2005. 